\title{
Internet, o la lógica de la seducción
}

\author{
Adriana Amado Suárez*
}

\section{Resumen / Internet, o la lógica de la seducción}

La autora focaliza la problemática de Internet desde las facetas que ubican a la red en sus interacciones sociales. Desde los ejes de análisis, que ubican a la red como objeto de prácticas del mercado, tales como la publicidad y el consumo, los servicios culturales, informativos y científicos, realiza un diagnóstico crítico en torno a las barreras de acceso a la red.

En continuidad con la vertiente crítica puntualiza los desafíos de la red en torno al problema de las identidades nacionales y regionales, en tensión con la globalización y el carácter cualitativo de la información disponible.

\section{Descriptores}

Calidad informativa / Comunicación social / Interacciones sociales / Internet / Navegantes / Negocios / Portales / Proyecto social y cultural / Publicidad / Realidad virtual / Tecnología

\section{Summary / Internet or the logic of the seduction}

The author focalizes Internet problematic from the faces that places the net in its social interactions. From the axis of the analysis, that place the net as an object of the practices of the market such as the publicity and the consumption, the cultural, informative and scientific services, a critical diagnostic is realized about the access barriers to the net.

The continuity with the critical flowing fixes the challenges of the net in connection with the problem of the national and regional identities, in tension with the globalization and the qualitative character of the available information.

\section{Resumo / Internet ou a logica da seduçao}

O autor focaliza a problemática da internet desde as facetas que colocam a Rede em suas interações sociais. Desde os eixos da analise que fica a Rede como objeto de prática do mercado tais como a publicidade e o consumo, os serviços culturais, informativos e científicos, faz um diagnóstico crítico em torno as barreiras de acesso à Rede.

Em continuidade com a vertente crítica sinaliza os desafios da Rede em torno do problema das identidades nacionais e regionais, em tensão com a globalizaçao e o caráter qualitativo da informação disponível.

Internet es una de las últimas innovaciones tecnológicas que han impactado en la forma en que la gente se relaciona con su entorno. Quizá por ello es que se haya constituído, por antonomasia, en el ícono de la modernidad, de la tecnología al servicio del hombre y de la globalización.

Su novedad y su naturaleza tecnológica ha dejado el desarrollo de este canal en manos de especialistas que han considerado como secundarios los aspectos sociales y culturales que todo medio de comunicación involucra. En un momento en que el entusiasmo indiscriminado por Internet se está atenuando resulta oportuno evaluar las prácticas y los usos desde una visión más abarcadora, que permita integrarla a la historia de los medios de comunicación, a los que Internet busca, sin lograrlo todavía, pertenecer. Si se preguntara a boca de jarro cuál avance tecnológico significó una revolución para nuestra

*Centro de Estudios en Diseño y Comunicación. infocedyc@palermo.edu

Adriana Amado Suárez: Profesora en Letras (UBA). Master en Comunicación Institucional (UCES). Profesora de la Universidad de Palermo. Doctorado en Ciencias Sociales en curso (FLACSO) 
sociedad finisecular, sin duda una gran mayoría mencionaría Internet. Aun sin conocer qué aporte puede brindar a la vida cotidiana. Distante de ser una certeza, ha sido indiscutiblemente una de las promesas más seductoras que ha dejado el siglo que pasa, al punto de haberse convertido en ciertos ámbitos en la gran epopeya. ¿Cuándo fue la última vez que un puñado de muchachos seducía a grandes grupos económicos con su creatividad y su empuje? ¿Cuánto hacía que una marca argentina no lograba imponerse en la mente de los consumidores del mundo? ¿Qué otro ejemplo tan contundente de la fuerza de la juventud empujando al establishment para que cambiara su foco de interés? Muestras de estas cuestiones han sido los emprendimientos de los sitios locales como El Sitio, Patagon, o De remate, que se convirtieron en el ejemplo a seguir de toda una generación que veía en el negocio de Internet la posibilidad de saltar del colegio secundario a la mesa de Directorio de un banco multinacional, sin escalas previas. Las fotos de un muchacho sin corbata y con la mochila al hombro saliendo de algún lugar en Wall Street se prendió con alfileres en los escritorios donde computadoras insomnes trabajaban sin otro pago que el de un pequeño talismán, que el mito bautizó como Stock Option, y que en pocos años -decía la creencia- redimiría a todos de la antigua costumbre de trabajar para vivir. La fábula, como tal, no tuvo un origen ni un autor, pero de su espacio digital se corporizó en los viejos medios de papel, portadores de las palabras sagradas contemporáneas. Los seguidores del credo sabían que la pantalla los conduciría a una sociedad sin tiempo y sin espacio, donde no era necesario salir a la hostilidad externa para conseguir los placeres mundanos, y donde cualquiera, sin más mérito que una computadora con conexión telefónica, podía acceder a todos los saberes que valieran la pena y a todos los lugares que pudieran ser conocidos. Y más aun, incluso sería posible llegar a ser miembro de una comunidad, cosa que la posmodernidad le había negado.

En este contexto es difícil alzar una voz disidente sin entrar en el grupo de los apocalípticos más retrógrados. Los intelectuales empezaron a buscar razones para apoyar el fenómeno y las casas de estudio se vieron obligadas a abrir sus puertas al saber que distraía a tantos jóvenes de los estudios de siempre. Hasta la Encyclopædia Britannica, símbolo de la quintaescencia del saber desde 1768 , supo que su futuro estaba en un CD ROM, o no estaba. Si tan venerable institución heredada del siglo de la llustración, sucumbió a una competidora totalmente espúrea, (una compilación de saberes triviales denominada Encarta, creada como estímulo de ventas de un sistema operativo) ${ }^{1}$, ¿qué esperar de los otros soportes educativos? ¿Cómo atraer al estudio entonces a una generación que parece no entender otra lógica más que la de las imágenes y de los saberes fragmentados? Como señala Virilio, "La mayoría de los intelectuales se han transformado en colaboradores, por no decir publicistas, del auge tecnológico (...) Internet, las autopistas electrónicas y los grandes holdings utilizan millones de dólares para promover sus productos. Ante esa realidad, no puedo sino ponerme la máscara de Casandra para mostrar la cara oculta de esta técnica, su negatividad" (Virilio, 1997: 52).

Quizás sea oportuno revisar, entonces, los mitos y verdades que circulan alrededor de esta tecnología, para comprender mejor sus alcances y analizar los aportes actuales y futuros que Internet puede dar a la sociedad.

\section{Breve historia de los medios de comunicación}

Muchos autores señalan que la era industrial ha sido superada por lo que llaman la sociedad informacional, en la que los bienes de cambio tradicionales se reemplazan por los intangibles de la información, que circulan mayormente dentro de canales y medios de comunicación. Sin embargo esta "Era de la información" que parece tan revolucionaria es apenas una parte minúscula de la historia de la humanidad. Tanto que -siguiendo el ejemplo que menciona Harper (1998)-, si uno imagina que los años vividos por el hombre pueden ser representados en 24 horas, el lenguaje humano, tal como lo conocemos, hubiera aparecido a las 21.30 horas, y la escritura, ocho minutos antes de la medianoche. En este ejemplo, los medios masivos de comunicación que ya parecen obsoletos, hubieran surgido once segundos antes de la medianoche, e Internet, apenas dos segundos antes de finalizar el día. Primera conclusión obvia: carecemos totalmente de una mínima perspectiva histórica para pronosticar el futuro de innovaciones tecnológicas que nos parecen tan radicales, cuyo impacto se empequeñece cuando se mira hacia atrás sin anacronismos.

Piénsese, si no, qué puede haber sentido un norteamericano adulto de mediados del siglo $X X$, que recordaba una niñez sin luz eléctrica, pero que había ido incorporando la radio, el 
automóvil, los ascensores y la televisión a su vida cotidiana. Este último invento, por ejemplo, se extendió tan rápidamente que diez años después de haberse comenzado a comercializar -esto es, a comienzo de los '50- ya estaba en el $85 \%$ de los hogares norteamericanos (Dominick, 1999). La computación, que nos parece tan revolucionaria, llega al público masivo de manera más gradual. En 1977 aparece la primera computadora Apple, que buscaba llevar a los hogares el principio de procesamiento de datos que se usaba en las empresas desde mediados de siglo. Cuatro años después aparece la primera computadora IBM con sistema operativo DOS, que fue reemplazado en la mayor parte de las computadoras por el programa Windows de la empresa Microsoft. Internet, nacida en los años '60 como un recurso militar, y luego utilizada en el ámbito académico, recién se abre al público a partir de 1991. Sin embargo, en marzo del 2000, sólo el $45 \%$ de la población de Estados Unidos -uno de los países con más alta penetración de Internetcontaba con acceso a la red (Fuente: www.census.gov y www.nua.ie), es decir, la mitad de velocidad con la que se expandió la televisión.

¿Cómo se sostiene esta conclusión a la luz de tantas publicaciones que hablan del éxito inigualable de Internet con relación a otros medios? En este punto influye el parámetro usado para explicar las estadísticas que sustentan tales conclusiones. Considérese, por ejemplo, que uno de los informes más citados para avalar la rápida penetración de la red es la investigación que hizo la consultora Morgan Stanley, que compara la cantidad de años que tardó la radio, la televisión, la televisión por cable e Internet en ser utilizada por 50 millones de personas, gracias a la cual se llega a la conclusión de que "La red es el medio de más rápido crecimiento en la historia". ${ }^{2}$ La limitación del enfoque es obvia: no es muy lógico comparar la población y sus condiciones estructurales a fines del siglo XIX, momento de aparición de la radio, y las del año 2000, por ello los resultados cambian totalmente cuando se reemplazan los números absolutos por valores relativos.

En esta misma línea de exitismo se ubican los agoreros que pronostican cambios radicales con el advenimiento de cada innovación tecnológica: en 1975 la revista Business Week anunció que en pocos años la informatización iba a llevar a la desaparición del papel en las oficinas. Para cualquier oficinista de fin de siglo el pronóstico suena tan absurdo como el del ocaso de los lápices, anunciado por el periódico New York
Times a raíz de la aparición de las máquinas de escribir (Seely Brown y Dugid, 2000).

Pero no resultaría productivo caer en el extremismo de despreciar el valor de Internet para compensar la desmesura de su estimación por parte de algunos sectores. La cuestión que se plantea es que la idolatría ha llevado a algunos a negar todo aquello que atente contra el ídolo. Internet es la superación de muchas limitaciones de los anteriores canales de comunicación, pero si sólo se habla de ella como si fuera perfecta, se dejan de lado aspectos cruciales que le impiden instalarse como un real medio de comunicación (por ahora, y haciendo honor a su propuesta, esta posibilidad todavía es virtual).

Se propone entonces considerar algunos aspectos que permitan evaluar la competencia de la red como medio de comunicación, es decir, Internet como fuente de información, como medio de comunicación tanto en su aspecto comercial como social. No sólo para pensar un futuro mejor para la red, sino para demostrar, también, que ya no es un problema de tecnólogos, que han hecho más de lo que la gente puede apreciar y utilizar, sino una cuestión de otros actores sociales, que deberían superar sus miedos o sus prejuicios para mejorar la propuesta que hoy da Internet, sobre todo para el gran público.

\section{De técnica de información a medio social de comunicación}

Antes de resolver si Internet es un medio de comunicación revolucionario, corresponde preguntarse si es efectivamente un medio de comunicación. Según Wolton, "para que haya comunicación de tipo mediático es necesario un vínculo entre el emisor, el mensaje y el receptor, es decir una representación de quién habla, a quién habla, mediante qué mensaje, con qué intención y a través de qué medio de recepción (...) no hay medios de comunicación sin representación a priori de un público" (Wolton, 2000: 110). Esta lógica sustentó los llamados sistemas de comunicación de oferta, que ofrecen una programación fija en función de una estimación del público al cual dirigen sus propuestas de programación. Y aquí reside la principal diferencia de Internet con los medios tradicionales. La Red es un sistema de información vastísimo y ubicuo, pero que por su naturaleza carece de una representación específica de una audiencia: cualquier persona en el mundo puede acceder a cualquiera de los 
sitios de información. Es éste, por ejemplo, uno de los grandes dilemas con los que se enfrentan los portales, que pretenden ser las vías de acceso a tal diversidad de información y convertirse en el punto convergente de propuestas -como un evolucionado canal de televisión- para audiencia de intereses incompatibles.

Por otro lado, los medios de comunicación son estables. Los lectores de periódicos basan su relación con un medio a partir de un sólido contrato de lectura, que determina tanto las expectativas del lector con relación a su periódico, cuanto el tratamiento que cada medio dará a las noticias. De manera similar, los televidentes conocen de antemano las reglas de comunicación, de modo que saben claramente cuál es el espacio de la ficción, de las noticias y de la publicidad, sin que tenga que estar indicado en cada caso. Las tecnologías, en cambio, son de por sí variables, y no ofrecen una condición de recepción clara para el navegante. Desde la imposibilidad de establecer la legitimidad de la fuente (¿cómo saber que la persona que suscribe una información es quien dice ser?), hasta la dificultad de encontrar un parámetro que registre las situaciones de intercambio informativo (¿cómo acceder a la página publicada ayer, en las mismas condiciones en que fue publicada?). Mientras el diario tiene una entidad común y un contenido informativo definido para cada una de sus ediciones, resulta difícil recuperar un mensaje emitido en Internet. Si el sitio decidió eliminar algún contenido, el navegante no tiene forma de reponerlo (una situación común es la de los archivos de consulta libre que luego de un período pasan a ser tarifados). Esta es la situación que aprovechan aquellos que ofrecen contenidos que pueden ser considerados ilegales, como la pornografía o los fanatismos ideológicos, que cambian de identificación y de servidor periódicamente para evitar su responsabilidad legal sobre los mensajes. Incluso en un ámbito de intercambio informativo que pueden considerarse totalmente ético, las direcciones, el formato, la ubicación de los archivos, los contenidos, cambian constantemente en Internet, resultando dificultosa cualquier referencia al pasado. Esto también crea resistencia entre los visitantes habituales, que se encuentran con cambios de formato cíclicos, que les dificultan la consulta (situación totalmente opuesta a lo que ocurre con los diarios impresos, que como saben que sus lectores resisten los cambios, introduciendo las modificaciones de estilo de manera gradual, para no atentar contra este contrato de lectura establecido).

Por otro lado, no puede olvidarse que la Red fue concebida primero para usos militares, después como lugar de intercambio académico, y actualmente, se prioriza su uso comercial. Es decir, que Internet no parece haberse pensado nunca a sí misma como un medio de masas, sino como un lugar de intercambio personal.

\section{La seducción del control}

¿Cuáles son las razones, entonces, para que muchos defiendan su carácter de medio de comunicación? Hay varias circunstancias que convierten a Internet en un medio muy atractivo. En primer lugar, significa un desafío al tiempo, porque el intercambio de información parece más rápido que en la comunicación humana (sensación que se tiene cuando se manda un mismo mensaje a cientos de destinatarios, pero que se diluye cuando uno debe contestar cada uno de los emails que recibe en la casilla). En segundo término, crea la ilusión de pertenencia a una comunidad, sin las desventajas de la interacción cara a cara: cualquier persona puede pertenecer a un canal de discusión sin tener que mostrar sus créditos académicos; o puede encarar una relación íntima sin siquiera tener que dar a conocer sus reales características personales. Todo lo cual genera una atractiva sensación de libertad de acción y de desafío a los límites geográficos o sociales: "La velocidad es el poder mismo" (Virilio, 1997: 17).

Pero el aspecto más interesante para proponer a la Red como un medio de comunicación es que permite una irrestricta circulación de comentarios, rumores, trascendidos, fanatismos, sin la responsabilidad que genera la misma información publicada en un medio masivo. Como señala Kelly, "Donde antes había un único fanático para cada idea, ahora hay una página web para cada idea de un fanático; muy pronto puede haber hasta 10.000 entusiastas para cada fascinación" (Kelly, 1999: 186).

Fascinación que se alimenta también desde los mensajes publicitarios, que plantean Internet como una necesidad y una condición para entrar ya no en el futuro, sino en el mundo actual. "No podés no tener tu email", exige el portal UOL, a la par que la empresa Oracle promete en nombre de la red "Todas las respuestas que Ud. necesita". En el mismo sentido, el eslogan de Microsoft desafía "¿Hasta dónde quiere llegar hoy?", ofreciendo para lograrlo un sistema operativo que permite manejar "Mi 
computadora" y "Mis documentos".

Esta sensación de control que ofrece la informática, es una clara ventaja con relación a los medios tradicionales. En éstos, el receptor es un espectador, término que tiene una connotación de pasividad frente al espectáculo del que es testigo. En los medios electrónicos se habla de 'navegantes', es decir de personas que eligen su ruta, y así lo muestra la etimología del término 'cibernética', tomada del griego kybernetiké ['h kubernhtikh], que es el 'arte de gobernar una nave'.

Llegado a este punto merece citarse una frase de Rousseau, que sentencia que "No hay forma más perfecta de dominio que aquella que preserva la apariencia de libertad". Y que es más que oportuna porque la libertad de los internautas no sólo es aparente, sino que está bastante acotada a ciertos grupos sociales y países.

Por empezar, el dato más contundente es que a marzo de 2000 sólo el $5 \%$ de la población mundial tenía acceso a Internet. Si se analiza además las cifras de participación por continentes sobre el total de navegantes, se aprecia una fuerte desigualdad, que reduce a una mínima expresión la cantidad de usuarios de este canal en países periféricos.

Esta situación se comprende al evaluar las razones estructurales y culturales que representan altas barreras para la penetración y masificación de esta tecnología. Dentro de las estructurales pueden señalarse la necesidad de contar con conexiones telefónicas, o los requisitos para el acceso y manejo de aparatos con elevado grado de complejidad, como son las computadoras. Aníbal Ford (1999) señala que los países más pobres tienen poco acceso a los teléfonos, condición necesaria para la conexión a Internet. Analizando las cifras que arroja el Informe sobre el desarrollo humano (PNUD, 1998), concluye que "a pesar de su antigüedad, el teléfono es menos democrático que la televisión" (Ford, 1999: 130). Para ilustrar someramente esta afirmación, considérese que Canadá tiene 59 teléfonos por cada 100 personas; Estados Unidos, 62,6; y España, 38,5 (estos tres países tienen 714, 8 y 404 televisores por cada mil personas, respectivamente). En el otro extremo, Brasil cuenta con 13,4 teléfonos por cada 100 habitantes; Argentina, 16; Sudáfrica, 9,5; Irán, 7,6; e India, 1,3 (que cuentan con 222, 219, 109, y 51 televisores por cada mil personas, respectivamente según el mismo informe). A ello se suman cuestiones culturales y sociales, que plantean dificultades para acceder a este canal, de diverso grado de complejidad. Y este aspecto plantea una de las tantas paradojas que conlleva Internet. Por un lado representa una posibilidad de acceso de sectores menos favorecidos económicamente a bienes culturales, pero por otro, al concepto de alfabetización, opone el de 'analfabeto funcional', que señala que el dominio de la lectoescritura no garantiza la posibilidad de manejo de una computadora y un adecuado acceso a la información. En este sentido, muchos también señalan el efecto discriminador de Internet, al acentuar la brecha entre los distintos segmentos socioculturales.

Ante este planteo, cabe aclarar que no se discute el valor de Internet como canal de comunicación. Es innegable que Internet "Es un sistema de transmisión y acceso formidable a un número incalculable de informaciones" (Wolton, 2000: 112). Sin embargo, se impone relativizar el valor de esta ventaja y contextualizarla en la realidad de cada sociedad.

\section{Usos reales y promesas virtuales}

Internet ofrece una serie de usos seductores: el uso de la web ofrece contenidos, entretenimientos, noticias, posibilidad de comprar en cualquier lugar del mundo sin salir de casa, formar parte de grupos de discusión, hablar (o mejor, chatear para usar el neologismo) con personas con las que uno no hubiera tenido contacto en la vida. Sin embargo, los internautas se empeñan en limitarse a usar servicios básicos: el correo y la búsqueda de información. Según un informe publicado en Harper (1998), una de cada tres personas utilizan Internet para recibir y enviar emails y para búsquedas de investigación; uno de cada seis lo hacen por la curiosidad que les despierta el medio, la misma proporción que lo hace para informarse de las noticias. Más restringidos son los usos relacionados con la información de negocios y financiera (uno de cada ocho personas), y con el entretenimiento (una de cada doce). Menos del diez por ciento se conecta a la red por trabajo o por temas educativos. Un informe de 1999 de la consultora Prince \& Cooke señalaba que la proporción se mantenía, habiendo aumentado a más del $90 \%$ los usuarios de servicios de correo electrónico (indicando también que sólo un tercio de los usuarios hogareños se conectaban con la World Wide Web). Una encuesta, publicada en el diario La Nación, y llevada a cabo en marzo de este año con usuarios de Capital Federal -el universo más privilegiado en lo que hace al uso de Internet en nuestro país- señalaba guarismos 
similares: $38 \%$ de los usuarios la empleaban para investigación o estudios, un 30\% para trabajar y un $26 \%$ para entretenimientos. ${ }^{3}$ En lo que hace a la gran promesa comercial de Internet, el e-commerce, los datos no son más alentadores. La misma encuesta antes citada señala que sólo el $3 \%$ del total de la muestra había hecho una compra por el canal electrónico. Sólo los grandes sitios han podido mantenerse como negocios prometedores (ya que todavía ninguno ofrece las pingües ganancias esperadas). Con la paradoja de que los artículos que más se venden en la red son... los libros, es decir, aquellos soportes que se amenazaba con desplazar. Tampoco los contenidos han cubierto las expectativas que se les habían puesto. Es cierto que Internet permite a los investigadores acceder a fuentes de información que hubieran sido excluyentes sin la red y permite que con el único costo de una llamada telefónica local, se acceda a medios de comunicación de cualquier parte del mundo (que obviamente tengan su sitio Web). El $60 \%$ de los lectores de la versión on line del New York Times jamás tuvieron un ejemplar impreso en sus manos, lo que muestra el aspecto poderoso que la red ofrece para la difusión de información. Pero paradójicamente los sites más visitados y las imágenes más bajadas se relacionan con la industria de la pornografía (razón por la que muchas empresas se vieron obligadas a restringir el acceso a la red de sus empleados), así como el $80 \%$ de los CD ROM's vendidos sean de juegos. Esto muestra el absurdo de especular con una demanda dirigida a los contenidos culturales considerados prestigiosos.

Esta desviación de los cibernavegantes hacia propuesta banales o poco esperables, también muestra el flanco más débil de la Web como vehículo de contenidos publicitarios. Los avisos en Internet comenzaron en octubre de 1994, con el primer banner vendido por Hotwired. En cinco años la industria de la tecnología puso altas expectativas en las posibilidades que brindaba Internet para los anunciantes. Tantas que llevó a que muchos proyectos de Internet basaran su plan de negocios principalmente en los ingresos por venta de espacios publicitarios. Las cifras muestran que incluso los sitios más visitados como www.yahoo.com o

www.lycos.com (recientemente adquirido por la multinacional Telefónica de España, para integrarlo en su portal www.terra.com), tienen un alto porcentaje de sus espacios publicitarios sin vender ( que representa el $40 \%$ o más en algunos sitios).
Este ha sido quizás el golpe más duro para los que veían en Internet su sueño de riquezas. Y también es el ejemplo de cómo la falta de un análisis cabal, hecho desde una perspectiva real y social, puede hacer fracasar el más promisorio de los proyectos. Las promesas virtuales se concretaron en eso: virtualidades que se proponían como originales por desconocer que muchas de las técnicas que se decían novedosas ya habían sido utilizadas antes, incluso cuando las compras hechas a distancia se hacían en vehículos de tracción a sangre (el e-commerce es heredero directo de la antigua compra por catálogo). Analizemos entonces algunos ejemplos de los factores que la publicidad y el comercio por Internet postulaban como prometedores y que fueron debilitándose por el uso y el comportamiento real de los usuarios. Promesa 1: Internet permite segmentar por contenido y contexto. La forma más sencilla de generar segmentación es por afinidad de las personas con la información que buscan o la actividad que mantienen en Internet. Este criterio, que determina la selección de un vehículo (programa de televisión o de radio) en función de la audiencia afín supuesta, se ha utilizado desde siempre en los medios masivos. La superación estaba en que la realimentación que ofrece un sitio de la red es inmediata y puede ser recibida directamente por el emisor. Esto es, una empresa que comunica en televisión depende de los informes de rating o de los posttest publicitarios para evaluar la efectividad de su comunicación, en cambio el anunciante de un sitio puede tener sus informes a diario. La realidad demostró que son muy pocos los anunciantes que pueden reaccionar con tanta flexibilidad y cambiar sus ofertas y contenidos publicitarios (por lo que sí funcionó para los sitios totalmente virtuales, en la administración de su propio contenido, como el caso de la librería virtual www.amazon.com).

Promesa 2: Internet permite conocer con exactitud el perfil de sus usuarios. Cada vez más las empresas acumulan datos de sus clientes actuales y potenciales con la esperanza de establecer un vínculo más personal y garantizar con ello su fidelidad. La realidad muestra que difícilmente haya una empresa que haga una explotación inteligente de los datos, principalmente por los costos del procesamiento adecuado de información. Prueba de ello son las administradoras de tarjetas de crédito, que conocen perfectamente los intereses, necesidades y debilidades de sus usuarios por el solo hecho de administrar sus pagos, pero rara vez usan estos datos para hacer una propuesta 
adecuada (los catálogos de productos que envían por correo son una muestra de que venden lo que tienen, estimulando al comprador a adquirir artículos que ni siquiera sabía que necesitaba). Nuevamente la velocidad era la ventaja de la red junto con los recursos de procesamiento que ofrecía para la administración de datos. Sin embargo, se encontró con dos obstáculos. Por un lado, el registro, para ser completo y eficiente, debe provenir del propio interesado, que no siempre está dispuesto a dejar sus datos sin garantía de confidencialidad (cosa que en nuestro país ni siquiera cuenta con un marco legal). Por otro, la misma virtualidad de la relación, es decir, la ausencia de un vínculo físico, implica un margen de error: o bien el usuario puede decir que es quien no es o que tiene pasatiempos que no cultiva, o bien puede suceder que sus compras o búsquedas no siempre tengan que ver con sus auténticos intereses (puede comprar libros por encargo de terceros, pero el programa asumirá que le interesan y seguirá mandando ofertas relacionadas a esa compra).

Promesa 3: Internet permite al sitio identificar al visitante. Esta tecnología hace posible saludar al usuario con nombre y apellido cada vez que ingresa al sitio, o recibirlo con una propuesta que responde al último pedido realizado, dado que permite identificar, por ejemplo, la computadora que se conecta al sitio (además de por cuánto tiempo, en qué momentos, con qué sistema operativo, de qué tipo de máquina se trata, etc.). Claro que esta información es anónima a menos que se cruce con otros parámetros más personales. La desventaja es que este método es intrusivo, es decir, atenta contra la privacidad del usuarios, así que los más expertos ya oponen tecnología (disponible gratuitamente en la red) para evitar la instalación en su computadora de cookies (nombre con el que se conoce a los archivos que permiten la posterior identificación). De todas maneras, un navegante puede ceder sus datos y autorizar la instalación de estos archivos, si esto le garantiza algún beneficio compensatorio. El problema es que los sitios raramente piensan en los beneficios para el consumidor, y se limitan a utilizar la tecnología para enviar más información publicitaria, que el navegante opta por ignorar, si no decide finalmente abandonar la visita del un sitio que se muestra tan desesperado por vender algo.

Promesa 4: Internet permite personalizar. La propuesta verdaderamente atractiva de Internet es que a los perfiles que el propio consumidor declara, se suman los que evidencia su comportamiento en la red, y los resultados del cruzamiento de datos con los de otros consumidores que tienen comportamientos similares. Por ejemplo, amazon.com brinda sugerencias de libros comparando compras de otros clientes interesados por los mismos títulos. Además, las variables son analizadas de manera dinámica y en tiempo real: esto significa que una vez identificado un dato, la comunicación se adapta de inmediato. Estos programas de análisis de perfiles y personalización se conocen como CRM (Customer Relationship Management) y constituyen la instancia de desarrollo por la que están empezando a transitar, o ya están transitando, todos los sitios de la red. ${ }^{4}$ Este recurso es lo que hizo que muchos hablaran de narrowcasting, en oposición de broadcasting, es decir la emisión de mensajes dirigidos a audiencias segmentadas -y por tanto más precisos y adecuados- como superación a los sistemas de emisión masivos, es decir, a audiencias indiscriminadas. Sin embargo, aquí también parece haber una confusión: "There is, however, an important difference between personalization and narrowcasting: in latter case, the individual still is receiving information packaged by someone else and it may arrive wether one requests it or not. What's novel about personalization, by constrast, is the ability of individuals to decide what information they receive an how they receive it" (Shaphiro, 1999: 46). Esta confusión entre narrowcasting y personalización, llevó a acuñar el concepto mass customization, oxímoron que alude a la posibilidad de personalizar... masivamente. Es decir, se pretende combinar lo mejor de los dos mundos: el poder de penetración de los medios tradicionales con la posibilidad de adecuarlo a cada individuo. Lo que muestra que aún la deseada personalización debe adaptarse a las leyes de la economía a gran escala para poder sobrevivir a las reglas del mercado.

Estas promesas a su vez alimentaban un nuevo proyecto publicitario, que confiado en su efectividad se construyó desde un modelo de pago por aviso visto, es decir, que garantizaba que los anunciantes pagarían sólo las comunicaciones efectivamente realizadas. El parámetro inicial -porque ahora convive con otros esquemas más tradicionales- de compra de publicidad en Internet es el CPM, que es el costo que tiene la aparición del logo o el elemento publicitario en mil oportunidades, con independencia del tiempo o el lugar de aparición. Sin embargo, el modelo ya está evidenciando ciertas limitaciones. Por un lado, los bajos índices de lo que se conoce como click 
through, o la gente que desde la publicidad ingresa a la página del anunciante, muy por debajo del $1 \%$, muestra que la visualización de una imagen no siempre garantiza la atracción efectiva del visitante. Es cierto también que en los medios masivos, la efectividad de la comunicación es un tema sin una solución, pero esta limitación se compensa con la llegada masiva del mensaje y, paradójicamente, su costo menor. Aquí se plantea el segundo aspecto que parece haber sido descuidado en la planificación publicitaria on line: los costos. Mientras los costos del CPM en Internet oscilan entre $\$ 20$ y $\$ 45$, según el sitio, el costo para llegar a mil personas a través de un programa de alto rating televisión es de \$12 (proporción que se mantiene tanto si se considera la TV de Estados Unidos como la de la Argentina)5. Si se compara con un aviso de una página en una revista dominical de un diario de alta circulación, el índice para las mil personas es de $\$ 25$, aproximadamente. Es decir, las cifras desalientan a los anunciantes, que prefieren todavía el impacto simultáneo y acotado geográficamente que dan los medios tradicionales.

Estas observaciones muestran que Internet se ha encontrado con algunas barreras para su crecimiento, la mayoría de las cuales surgen de la imprevisión de los ideólogos de la red, o de subestimar el poder de los medios conocidos. La industria cometió aquí el pecado de soberbia y la publicidad pecó también de exceso de humildad. Los expertos tradicionales se consideraron analfabetos funcionales y por dignidad se retiraron de la escena digital, dejando el tema en manos de soñadores y programadores, que conocían mucho de código HTML pero poco del comportamiento real del consumidor. Es decir, otra vez, la irreflexión determinó la acción.

\section{Virtual o real: ésa ya no es la cuestión}

Si Internet quiere consolidarse como medio de comunicación debe enfrentar varios desafíos, dado que la tecnología de suyo no crea comunicación, a menos que se trabaje en un proyecto cultural y social.

Existen tres tipos de comunicación: la directa, es decir el intercambio comunicativo entre individuos; la tecnológica, o de las tecnologías que sirven a los procesos de comunicación, y la comunicación social y política. Entonces "El problema que presenta la ideología tecnológica propia de las nuevas tecnologías de la comunicación radica en que cuando se determina la dimensión tecnológica, se subestima la importancia de los datos culturales y sociales; incluso se llega a creer que el cambio tecnológico es el principal factor de cambio, mientras que el modelo cultural y el proyecto social se consideran como secundarios" (Wolton, 2000: 228). De ahí que en nombre de la globalización se pretendiera instalar los mismos modelos de Internet en todos los países, y la condición de éxito de un sitio fuera la cantidad de países en los que tiene presencia activa. La realidad mostró que no sólo era cuestión de traducir las páginas a varios idiomas. Es por ello que "un número considerable de países con identidades mal asentadas se enfrentan al poder de las industrias de la comunicación, las cuales en nombre de la modernidad, del libre intercambio, de la hibridación de culturas y de la mundialización, desean hacer tambalear los reglamentos frágiles a favor de la identidad nacional para alabar los méritos de los 'nuevos medios de comunicación'" (Wolton, 2000: 78). Pero las cadenas de televisión que buscaron mundializar su oferta informativa, comprobaron que las audiencias les están siendo esquivas, al igual que los portales descubren que su propuesta global sólo es posible con la adecuación local de contenidos y lenguaje.

Por otro lado, el problema ya no es el acceso a la información sino desarrollar la capacidad de qué buscar. No todo puede ser "Hágalo Ud. mismo": tenga su propia página, edite su propio periódico, realice su tesis doctoral sin tutoría. Cada vez hacen falta más intermediarios que sepan capitalizar las funciones de selección y legitimación de la información. No en vano siguen siendo los medios con existencia real, como diarios o cadenas de televisión, los que reciben más consultas en sus sitios. Pero precisamente este ejemplo muestra que el medio no es el soporte: el diario no es el papel ni la pantalla. Es algo más, y por eso más que nunca resulta necesario que Internet se integre a otros medios de comunicación y canales de información, en lugar de desestimarlos. Los diarios por ejemplo, han descubierto el valor de la sinergia: el último congreso de la Asociación Mundial de Periódicos (WAN) mostró un crecimiento de la circulación de diarios, en muchos casos motivada por la incorporación de jóvenes lectores que se pusieron en contacto con la prensa gracias a Internet. ${ }^{6}$

Si se valora el aporte de Internet a la educación, queda claro que la lógica es la inversa: es decir qué puede tomar la educación de Internet. En este campo, la red brinda inmejorables 
oportunidades: manejo de tecnologías culturales masificado, aprovechamiento de técnicas para lograr una enseñanza ilustrativa y facilidad de acceso a publicaciones y bancos de datos (Schulz ${ }^{7}$ en Thesing y Priess, 1999: 393). Sin embargo estas ventajas no atemperan los riesgos, dentro de los cuales el más peligroso es el del aumento de la brecha de conocimientos: "la multimedia confirma una teoría ya conocida en la ciencia de la comunicación: la teoría del abismo de los conocimientos (...) ver televisión hace más inteligentes a los inteligentes y estupidiza más a los estúpidos" (Bergsdorf ${ }^{8}$ en Thesing y Priess, 1999: 87). Este punto lleva a reflexionar a su vez acerca de un emprendimiento educativo oficial, un portal denominado www.educ.ar, impulsado por la donación millonaria de un particular y apoyado por el Ministerio de Educación, que busca proveer a todas las escuelas del país de acceso a internet. Es obvio que la igualación tecnológica no nivela de por sí la multiplicidad de factores culturales y sociales que atraviesan la condición educativa de los alumnos y docentes de todas las escuelas del país. De hecho, el acceso al medio no está determinado solamente por la conexión o por el soporte tecnológico (que es lo que prevé el proyecto inicialmente), sino también -y fundamentalmente- por la capacidad de aquellos a los que va dirigido de incorporar y utilizar adecuadamente los beneficios que ofrece. Un ejemplo contundente de ello es que menos del $2 \%$ de los contenidos informativos en internet están en idioma español (Ford: 1999), lo que muestra que la competencia idiomática es factor de exclusión contundente si se quiere aprovechar el medio en su globalidad. Es obvio que es un paso importante para mejorar las condiciones de acceso a los bienes culturales de todas las escuelas del país, pero deberá estar acompañado por un proyecto social, para que el beneficio tecnológico brinde sus frutos. Como manifestó Roger Chartier en un artículo publicado en Le Monde "En un mundo castigado por el analfabetismo y desgarrado por desigualdades y exclusiones, la tarea de la educación requiere una toma de conciencia colectiva y decisiones políticas muy alejadas del futuro ideal que prometen los profetas (interesados) de la felicidad electrónica". ${ }^{9}$ Relacionado con este tema está la cuestión de los libros y su función como soporte educativo. Porque si bien por un lado, la red brinda la posibilidad de acceso a material inédito o de ediciones agotadas, complementando la oferta editada, debe tenerse en cuenta que la versión digital implica una pérdida del mensaje que ofrece el contenido impreso. Además la multiplicidad y fragmentación no siempre son aliadas de la calidad educativa. "La preferencia por la multiplicidad fragmentaria de materiales y el consiguiente rechazo del libro, oculta el miedo a la confrontación con un mundo enunciativo singularizado. Es en definitiva, un miedo al Otro" (Verón, 1999: 146), miedo que se transforma en el vacío que la propiedad intelectual encuentra en Internet. A la posibilidad de editar un libro sin depender del circuito comercial, ventaja indiscutible de la red, se opone la falta de protección de los derechos de autor. En el mismo sentido se plantea la trivialización de las propuestas culturales y su relación, muchas veces oculta, con propuestas publicitarias o proyectos comerciales. Un ejemplo de esto es el lanzamiento del último libro del escritor Ernesto Sábato, que prometía su versión digital en Internet y que tematizó en los medios periodísticos la cuestión de los libros digitales durante la semana previa al lanzamiento de la obra, pero que apuntaba principalmente a la estrategia de promocional de la editorial y los medios asociados.

Otro aspecto a considerar es la función de Internet como fuente de información, caso en el que debe luchar contra dos limitaciones. Por un lado superar la saturación informativa que brinda un medio con más de un millón de sitios registrados. Pero por otro, y más importante, garantizar la confiabilidad de las fuentes. $Y$ en este punto, al aspecto educativo, se suma el periodístico.

Ramonet da un ejemplo al referirse al Caso Lewinsky, que comprometía al presidente Clinton con una becaria de la Casa Blanca: "un tal Matt Drudge envió a su servidor de Internet el contenido de las conversaciones telefónicas grabadas por la amiga denunciadora de Lewinsky, Linda Tripp. La revista Newsweek había dudado en difundir esas informaciones, tomándose tiempo para verificar la información. Pero Matt Drudge no albergó ninguna duda" (Ramonet, 1998:14). Esto muestra como la ventaja es a la vez un gran riesgo, porque la velocidad de información no siempre es garantía de veracidad, y puede ser un factor que melle la confianza de la red como fuente de información. De hecho, según una investigación que hizo la publicación estadounidense Brill's Content, de las 51 historias publicadas en www.drudgereport.com entre enero y septiembre de 1998 , sólo 11 eran verdaderas. ${ }^{10}$ Como señala Al Neuhart, fundador del diario estadounidense USA Today, "Lo que debe preocupar a los periodistas es encontrar formas de reunir información de una manera cada vez 
más cuidadosa, más confiable, sea para los diarios, para la televisión o para Internet (...) Todas las decisiones son difíciles cuando se trata de presentar noticias para el público". ${ }^{11}$

\section{Desafíos de Internet: del narcisismo a la socialización}

Muchas de las paradojas señaladas surgen del choque entre la información que circula en la prensa y la que es producto de una investigación y una reflexión subsidiarias. La contradicción surge entre los presupuestos y los resultados, o entre datos en apariencia complementarios, pero que un análisis profundo muestra por lo menos contradictorios.

Por eso como primera medida es necesario contrarrestar lo que Debray llama el 'narcisismo tecnológico', que se evidencia en el hecho de que "los mass-media cada vez hablan más de los mass-media. Y en los periódicos, la página 'comunicación' se agranda a la vez que se reducen las informaciones (del mundo exterior). Con ello se demuestra que en un mundo íntegramente mediatizado las mediaciones no pueden ya sino mediatizarse también, hasta borrar ese espacio vacío, esa carencia exterior que hasta ahora había estructurado como un remordimiento nuestro fuero interno y al que llamábamos 'lo real'." (Debray, 1998: 254) Porque así como durante el último año mucha prensa se ha dedicado a hablar graciosamente del 'boom de Internet', de 'los billonarios de la red', entre otros clichés, ahora a la luz de algunos fracasos, ha comenzado un mea culpa de signo contrario. Una muestra de ello son las notas que publicaron los diarios de mayor circulación los últimos meses: "Millonarios virtuales: Son muy jóvenes, sus sitios en Internet valen oro. Pero tienen los bolsillos vacíos.", planteaba en la tapa la revista La Nación, del 21 de mayo de 2000, o más directamente el suplemento económico del diario Clarín del 9 de julio de 2000 pronosticaba en su nota de tapa "Fin de Fiesta: Las empresas de Internet luchan por sobrevivir", citando como referencia un informe del Gartner Group que determina que desaparecerán 9 de cada 10 empresas (claro que este informe ya tenía tres meses circulando en Internet, es decir se conocía antes de que la comitiva presidencial presentara ante el presidente de los Estados Unidos a los empresarios "punto com" de la Argentina como promesa del desarrollo del país). Este incipiente derrotismo reemplaza al exitismo de los meses anteriores, pero uno y otro no dejan de ser lo mismo con diferencia de grado. Internet no es ni dios ni el diablo, pero puede ser las dos cosas al mismo tiempo. Sería más saludable para la red que el fracaso sea analizado desde los errores de apreciación que generaron las expectativas desmesuradas que el canal no pudo cubrir. Es la misma deducción de aquellos que niegan el valor de la televisión pública porque no ofrece una programación culturalmente aceptable. Nuevamente el error está en confundir el mapa con el territorio.

Y que se plantee la necesidad de abrir el juego al mundo real. Internet no necesita una comunidad virtual, sino usuarios reales con necesidades reales, interpretadas desde profesionales que conozcan el mundo real. Éste puede ser el camino para aprovechar el verdadero potencial de Internet y su poder democratizador, en el de la apreciación Umberto Eco: "Hay un universo al estilo Orwell, fundado sobre tres clases, ya no marxistas: los que están en interrelación activa con la red, la pequeña burguesía de usuarios pasivos (como, por ejemplo, el empleado de una compañía aérea que utiliza la pantalla para conocer el horario de los aviones) y la clase proletaria, que lo único que hace es mirar la televisión. Y como el hijo de una familia pobre puede aprender rápidamente a utilizar Internet, la división de clases ya no estará más fundada en torno a la riqueza." 12

\section{Notas}

1 Veáse el interesante análisis que realiza Aníbal Ford (1999) con relación a los contenidos educativos que ofrece este soporte.

${ }^{2}$ Hyland, Tom. "Why Internet Advertising?".
En www.iab.net.

${ }^{3}$ Encuesta "Uso y acceso a Internet en la Capital Federal", realizada por el Centro de Investigación y Finanzas de la Universidad Torcuato Di Tella, www.utdt.edu/ departamentos/empresarial/cif/cif.htm. (Encuesta telefónica por sistema C13 CATI, sobre 302 casos, en febrero de 2000, con error estadístico +/- 5,5\%). Publicada en el diario La Nación, edición del 23 de abril de 2000, Sección 2, p. 4.

${ }^{4}$ Los principales proveedores de este tipo de programas de personalización son Art Technology Group (www.atg.com), Broadvsion (www.broadvision.com), Net Perceptions (www.netperceptions.com), y GuestTrack (www.guesttrack.com).

5 Boyce, Rick, "Exploding the Web CPM Myth", publicado en www.iab.net.

${ }^{6}$ Véanse los artículos "La lectura de la prensa escrita aumenta en numerosos países a pesar de Internet" (diario El País, Madrid, No 1503, 14.6.2000); Claudio 
Escribano, "La prensa goza de buena salud" en diario La Nación, Buenos Aires, 13.6.2000; y Fernán Saguier,

"Internet no es enemiga de los diarios, fomenta la lectura" en diario La Nación, Buenos Aires, 26 de marzo, 2000.

${ }^{7}$ Winfried Schulz, "Nuevos medios de comunicación: oportunidades y riesgos", en Thesing y Priess, 1999, pp. 385-418.

${ }^{8}$ Wolfgang Bergsdorf, "La gran responsabilidad de los medios en la sociedad informática", en Thesing y Priess, 1999, pp. 81-93.

${ }^{9}$ Reproducido por el diario Clarín, edición del 12 de junio de 2000, bajo el título "Falsas promesas de felicidad electrónica".

10 "Drudge Report: el amarillismo en Internet", publicada en la revista Un Ojo Avizor, Buenos Aires, N 10, marzoabril de 1999.

${ }^{11}$ Grillo, Cristina, "Jornais e Internet se complementam: Al Neuharth, que ajudou a fundar o 'USA Today não crê em conflito", Folha de São Paulo, San Pablo, 19 de junio, 2000, p. 12

12 Eco, Umberto, citado por Eduardo Febbro, en "La pelea del siglo" en Radar, 23 de enero, 2000, p. 14.

\section{Bibliografía}

\section{Adorno, Theodor}

(1998), Minima moralia, Madrid, Taurus

\section{Costa, Joan}

(1992a), Imagen pública. Una ingeniería social. Madrid, Fundesco.

(1992b), Reinventar la publicidad. Reflexiones

desde las ciencias sociales, Madrid, Fundesco.

\section{Dayan, Daniel (Comp.)}

(1997), En busca del público, Barcelona, Gedisa.

\section{Debray, Regis}

(1998), Vida y muerte de la imagen, Barcelona, Paidós.

\section{Dominick, Joseph}

(1999), The dynamics of mass communication, Boston, McGraw Hill.

\section{Eldin, François}

(1999), El management de la comunicación, Buenos Aires, Edicial.

\section{Ford, Aníbal}

(1999), La marca de la bestia, Buenos Aires, Grupo Norma.

Gauthier G., André G. y Mouchon, J. (Comps.)

(1998), Comunicación y Política, Barcelona, Gedisa.

\section{Kelly, Kevin}

(1999), Nuevas reglas para la nueva economía, Buenos Aires, Granica.

\section{Harper, Christopher}

(1998), And that's the way it will be: news and information in a digital world, Nueva York, New York University Press.

\section{Konrad Adenauer Stiftung}

Contribuciones. Año XVI - N² (62) abril-junio 1999.

\section{McLuhan, Marshal y Quentin Fiore}

(1997), El medio es el masaje. Un inventario de efectos, Barcelona, Paidós.

\section{McKenna, Regis}

(1998), Tiempo real, Buenos Aires, Temas Grupo Editorial.

\section{Negroponte, Nicholas}

(1995), Ser digital, Buenos Aires, Atlántida.

\section{Piscitelli, Alejandro}

(1998), Post/Televisión. Ecología de los medios en Internet, Buenos Aires, Paidós.

\section{Price, Vincent}

(1992), Public opinion, California: Sage Publications

Trad. cast. La opinión pública. Esfera pública y comunicación, Barcelona, Paidós, 1994.

\section{Priess, Frank y Fernando Tuesta Soldevilla}

(1999), Globalización, democracia y medios de comunicación. Buenos Aires, CIEDLA

\section{Sarlo, Beatriz}

(1996), Instantáneas: medios, ciudad y costumbres en el fin de siglo, Buenos Aires, Ariel.

\section{Ramonet, Ignacio}

(1998), La tiranía de la comunicación, Madrid, Debate.

\section{Sartori, Giovanni}

(1998), Homovidens: La sociedad teledirigida, Madrid, Taurus.

\section{Seely Brown, John y Paul Dugid}

(2000), The social life of information, Harvard University Press

\section{Shapiro, Andrew}

(1999), The control revolution: how the internet is putting individuals in charge and changing the world we know Nueva York, Public Affairs.

\section{Thesing Josef y Frank Priess}

(1999), Globalización, democracia y medios de comunicación. Buenos Aires, CIEDLA.

Verón, Eliseo

(1999), Esto no es un libro. Barcelona, Gedisa..

Virilio, Paul

(1997), Cibermundo: ¿Una política suicida? Santiago, Dolmen/Granica.

\section{Wolf, Mauro}

(1987), La investigación de la comunicación de masas Barcelona, Paidós.

(1994), Los efectos sociales de los media

Barcelona, Paidós

\section{Wolton, Dominique}

(1995), Elogio del gran público. Barcelona, Gedisa. (2000), Internet, ¿y después? Una teoría crítica de los nuevos medios de comunicación. Barcelona, Gedisa. 